\title{
Craft and Science in the Treatment of Traumatized People
}

\section{Citation}

Herman, Judith Lewis. 2008. "Craft and Science in the Treatment of Traumatized People." Journal of Trauma \& Dissociation 9 (3) (July): 293-300. doi:10.1080/15299730802138966.

\section{Published Version}

$10.1080 / 15299730802138966$

\section{Permanent link}

http://nrs.harvard.edu/urn-3:HUL.InstRepos:35641729

\section{Terms of Use}

This article was downloaded from Harvard University's DASH repository, and is made available under the terms and conditions applicable to Other Posted Material, as set forth at http:// nrs.harvard.edu/urn-3:HUL.InstRepos:dash.current.terms-of-use\#LAA

\section{Share Your Story}

The Harvard community has made this article openly available.

Please share how this access benefits you. Submit a story.

Accessibility 
Craft and Science in the Treatment of Traumatized People

Judith Lewis Herman

Department of Psychiatry

Harvard Medical School

Boston, MA

Victims of Violence Program

Department of Psychiatry

The Cambridge Hospital

Cambridge, MA

Correspondence concerning this article should be addressed to Judith Herman, M.D.

E-mail: herman.j@comcast.net

$$
\begin{aligned}
& \text { aceopted redentorid }
\end{aligned}
$$

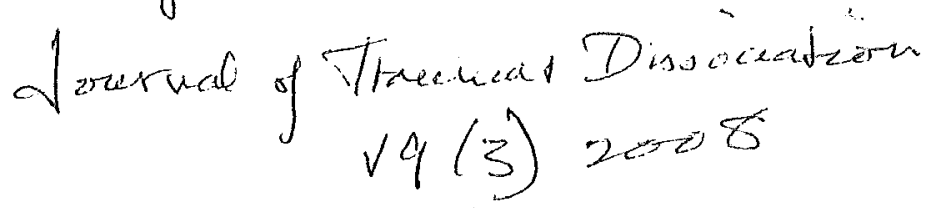


In a beautiful little book called Language and Problems of Knowledge, Noam Chomsky (1988) presents his reflections on "the attempt within contemporary science to approach traditional questions in philosophy and psychology in the light of what we now know or may hope to learn ... about the brain." The essays in the book were originally public lectures delivered to a general audience. In the discussion following the lectures, someone in the audience asked how the basic science of linguistics could be applied to teaching languages. This was Chomsky's reply:

"People who are involved in some practical activity such as teaching languages, translation, or building bridges (and I would add here, practicing psychotherapy) should probably keep an eye on what's happening in the sciences. But they probably shouldn't take it too seriously, because the capacity to carry out practical activities without much conscious awareness of what you're doing is usually far more advanced than scientific knowledge. The history of the physical sciences is interesting in this respect. Engineers knew how to do all sorts of complicated and amazing things for hundreds of years. It wasn't until the mid-nineteenth century that physics began to catch up and to provide some understanding that was actually useful to engineers. Now physics in the nineteenth century was vastly more advanced than our understanding of languages (or psychology) today, and building bridges is much less complex than what is actually taking place in the teaching of languages or translating (or the practice of psychotherapy)." (Text in italics added, ЛLH.)

Some form of psychological healing is probably practiced in every culture. While the varieties of healing techniques are virtually numberless, I believe that all healing practices share two basic commonalities. The first is the establishment of a privileged 
relationship between the patient and the healer, a relationship with sacramental social rules. The second is the practice of the talking cure: putting feelings into words, and unburdening shameful secrets. Folk wisdom has long recognized the value of psychological healing for both physical and mental health. We are now just beginning to document the efficacy of some forms of psychotherapy in more systematic empirical studies (Foa, Keane \& Friedman, 2000; Westen \& Morrison, 2001). But exciting as these studies may be, so far they simply demonstrate what practitioners already know, namely, that psychotherapy often works, and sometimes it works really well; that is, it not only relieves the patient's target symptoms or chief complaint, but it also produces global improvement in health, well-being, and social adaptation. I would submit that at our current level of scientific understanding, we do not really know how psychotherapy works (when it does work), or why it doesn't work (when it doesn't). Though we may aspire to the status of a science, the practice of psychotherapy is a craft.

Craft traditions have many strengths. They are strongly embedded in the practicalities of daily life, and as such are constantly subjected to empirical (though unsystematic) tests of utility. They preserve a highly complex body of knowledge and skill, resisting reductive standardization. They are taught relationally, through a long apprenticeship which fosters discipline, high standards for performance, and an ethic of care. Within their disciplined forms, crafts permit wide scope for individual imagination and creativity.

Craft traditions also have many weaknesses. Because crafts are highly complex and resistant to reductive standardization, successful practice depends on individual skill, which is highly variable. Training through long apprenticeship fosters the development 
of authoritarian personality cults, schools of master craftsmen and their disciples. These schools or sects can become secretive, stagnant, ritualized in their practice and grandiose and dogmatic in their claims. Examples from psychology abound: one has only to mention the psychoanalytic, behavioral, family therapy and expressive therapy schools and the manifold schisms and sects within them, each named for its ruling patriarch.

The good news is that practitioners of many different schools are becoming more courageous about opening up their work to observation. I am continually struck by the disparity between the richness and complexity of what therapists actually do, and our limited capacity to conceptualize or even accurately to describe what we are doing. We try to find a language for it, but most of the language is not particularly illuminating, and sometimes it actually hinders understanding. (E.g. a recent cartoon: Analyst to perplexed patient: "OK, what part of 'malignant regression and pathogenic reintrojection as a defense against psychic decompensation ' don 't you understand?")

Recently I observed a videotape of a psychotherapy session. The therapist, Pat Ogden, is the Director of the Sensorimotor Psychotherapy Institute in Boulder CO. During the course of the videotaped therapy hour, Ogden skillfully guided the patient, a trauma survivor, through an intense, cathartic emotional reaction. Narrative memory of the trauma, imagery, emotion, and bodily experience all came together, and the patient was able to make new meaning of her experience. It was a beautiful piece of integrative work. However, much as I admired what Ogden had done, I did not find it particularly novel or unfamiliar. So I wondered: have I really been doing Sensorimotor Psychotherapy all along without knowing it? No, of course not; but, I would submit, neither has she. She's been doing psychotherapy, directing special attention toward the 
bodily experience of emotion. This is a well-known and quite reliable technique for accessing strong feelings in emotionally constricted patients (and many trauma survivors are profoundly constricted). Ogden has elaborated and systematized this technique with a signature style, as befits a master craftswoman (Ogden, Minton \& Pain, 2007).

If I translate what Ogden does into a Rogerian conceptual framework, I would talk about the active principles of her successful therapy as accurate empathy, nonjudgmental warmth, and genuineness. In pioneering psychotherapy research conducted a generation ago, these were the variables that consistently predicted successful treatment outcome, regardless of the therapist's professional discipline, theoretical school, or specialized technique (Truax \& Carkhuff, 1967). If I translate Ogden's work into the language of my own preferred conceptual framework, I would talk about the active principles of her psychotherapy as empowerment and relational connection (Miller \& Stiver, 1997). I would notice her attitude of deep respect for the patient and her sensitivity to the patient's autonomy and choice. I would call attention to her exquisite empathic attunement, her ability to maintain a relational connection with her eyes, voice, words, laughter, and, occasionally, touch. I would note her superb timing in the moment-to-moment conduct of the session. I think it is unlikely that a less skilled practitioner could produce the same result using nominally the same technique.

Conversely, I would argue, the same result, integration of a traumatic memory, can be achieved by means of any number of other techniques. One sees the same kinds of responses, for example, in trauma-focused groups, where the relational connections among group members help patients overcome their dissociative reactions (Herman \& Schatzow, 1984). I don't doubt that skilled practitioners of hypnotherapy, EMDR, 
various forms of expressive therapy, psychodynamic therapy, or cognitive-behavioral therapy can all achieve similar results with some patients. The operative words are skilled practitioners and some patients.

Are there significant differences in effectiveness among the psychotherapies for traumatic disorders? At this point, we really don't know. Some of the simpler forms of therapy lend themselves to standardization much more readily than others, so at this point we have collected the most systematic empirical data about them. However, this very standardization creates a treatment model so limited and inflexible that it is not appropriate for many if not most traumatized people (Spinazzola, Blaustein \& van der Kolk, 2005). The state of current knowledge should not be arbitrarily restricted to treatment outcome findings that can be demonstrated rigorously within the constraints of the very crude methodologies that have so far been developed. We are nowhere near to establishing a gold standard in trauma treatment.

I suspect that, if we were able to study psychotherapy as systematically as we now study, say, antidepressants, we might find many analogies between psychotherapy and psychopharmacology. For example, we don't really understand in any deep or fundamental way how antidepressants work, but fortunately we don't need this level of understanding in order to use them effectively. In randomized, controlled clinical trials, we observe that $1 / 3-2 / 3$ of patients with a depressive episode will have a good response to any particular antidepressant. That is better than a placebo response, though not as much better as we would like. Of course, most of the patients we see in practice are far more complicated than the patients studied in clinical trials, but let's say, for the sake of argument, that we can still expect similar results under naturalistic conditions. Overall, 
as far as we know, none of the antidepressants has a significantly better success rate than the others; rather, each one seems to work best with a different group of people (Rush, et. al., 2006).

When we prescribe, we have to figure out which antidepressant is right for each particular patient. Even in the simplest cases, we don't currently know how to predict a successful fit. Most practitioners become familiar with a few medications and learn the nuances of prescribing within that repertoire. It turns out that some lucky patients will respond well to just about any of the medications, while about $10 \%$ or more won't respond to anything currently available. For the rest, we resort to trial and error. It would be nice if we had some systematic basis for determining which medication will be best for which patient, but we don't, so we use our clinical instincts, for lack of a better guide. Pharmaceutical companies may attempt to persuade us that one or another product is superior to all the others, but these are claims of marketing, not science (Goode, 2002).

The same may be true of the many psychotherapies for psychological trauma. We see some patients, particularly adults in good health with good social supports who suffer a single-incident trauma, who will probably do reasonably well with any of a wide range of treatment or self-help options. We see some patients at the extreme end of the complex trauma/dissociative disorder spectrum who may be beyond the reach of any treatment currently known. In between are all the rest; patients who may respond well to one form of treatment but not another, and as yet we don't know very well how to predict the best match. We recognize that treatment of trauma is a complex biological, psychological and social project that unfolds in stages over time and may involve many different treatment modalities to reach a stage of optimal recovery (Herman, 1997). 
The following vignettes illustrate two different forms of trauma and two different paths to recovery. Both are based on cases that I have supervised and the Victims of Violence Program in the Department of Psychiatry at Cambridge Hospital. Specific details that might lead to recognition of the patients have been disguised.

The first patient was a man in his early 40 's who had recently arrived in Boston as a refugee. Referred by his legal services attorney for evaluation to support his political asylum application, he presented with classic, severe PTSD and major depression. He was preoccupied with fear of deportation, and firmly stated that he intended to commit suicide rather than return to his native country. Response to medication was unimpressive, and he was not interested in psychotherapy, but he did form a positive attachment to the clinician who conducted his political asylum evaluation. He was very grateful when she furnished a supportive letter and offered to testify at his INS hearing.

This man's PTSD symptoms improved dramatically the day he received notification that his political asylum application had been approved. For the first time in years he was able to sleep through the night. Having established a trusting relationship with the therapist, he returned for a brief course of psychotherapy, focusing on grieving for his family, who were missing and presumed dead.

When I reviewed the case with the treating clinician, she expressed feelings of helplessness and hopelessness. What could she possibly offer this man who had lost everything? But her presence as an engaged and empathic witness had opened up the possibilities of restored attachment. Soon after starting treatment, the patient reported that he had joined a soccer team and was playing regularly. His numbing and depression 
lifted as he found his own pathway to recovery, a pathway of active physical mastery in connection with others.

In this case, the dominant emotions were terror and grief. Recovery began, as it always does, with the establishment of safety. I would suggest that the therapist's willingness to offer concrete assistance with the patient's immigration claim was a necessary precondition for any form of therapeutic alliance. Her action in solidarity with a survivor of political persecution created the possibility of restored faith in other people. Thereafter, he didn't need anything fancy. With a little bit of grief work and traumafocused psychotherapy, the patient found his own creative way to integrate the body in recovery and a time-honored way to form new social relationships.

The second patient was a single professional woman in her late $20^{\prime}$ s who sought therapy after the breakup of a love affair. She had cut her wrists, but she insisted that she did not intend to kill herself; cutting was just one of the many secret things she did. She described a chaotic and tormented love life, which contrasted with her strong and accomplished persona in the world of work. This patient described symptoms that would meet criteria for PTSD and raise questions of a dissociative disorder. But these symptoms were not what drove her to seek treatment; rather, it was the corruption of her sense of self, her sexuality, and her capacity for intimacy. She reported that her father had molested her repeatedly from early childhood until she began dating in adolescence. Since that time, the patient had had numerous brief sexual relationships and several coerced sexual encounters which she had never defined as rape.

In weekly psychodynamic psychotherapy that unfolded over a period of two years, the patient gradually came to understand her risky and degrading sexual 
relationships as re-enactments of incest. She was able to recall how lonely she had been as a child, and how much she had missed her absent mother, as she slowly developed empathy for the childhood longings that had left her vulnerable to exploitation. A turning point occurred when the patient found herself sobbing uncontrollably at the news of her therapist's vacation, and was then able to connect with childhood feelings of sadness, fear and rage at her mother's failure to protect her (yes, Virginia, there is a transference). In the last months of her treatment, this patient joined a trauma-focused group, where other survivors disclosed histories and problems similar to hers. For the first time she felt a sense of belonging. By the end of the group, she reported feeling freer and more accepting of herself and she had begun a promising new love relationship.

In this case, the dominant emotion was not terror but shame. In passing I would point out that while we are starting to understand something about the psychobiology of fear, we know almost nothing about the psychobiology of shame, an equally powerful, contagious, and potentially toxic emotion. One reason for this is that we can not study shame in the rat. Shame is a state of unbearable self-consciousness; so it is found only in living creatures whose consciousness includes a sense of self. Shame is also a social emotion; it is a universal human reaction to rejection, humiliation, or defeat. Though shame is experienced powerfully in the body and about the body, it is not relieved primarily by physical means; rather it is relieved by the affirmation of restored relational connection. Shame dissipates with mutual regard, when people look each other in the eye and laugh together (Lewis, 1971). That is why I would propose that relational psychotherapies, both individual and group, have such a powerful effect in the treatment of people who have been exploited and humiliated by those they love. 
These two vignettes are presented as a reminder that the range of psychological trauma is very broad, calling for diversity and flexibility in the range of treatment approaches. Let us welcome and embrace this diversity. Though the practice of psychotherapy is still a craft, this does not mean that we have to perpetuate the worst features of craft guild behavior, by clinging to sectarian allegiances and claims. In physics one does not find Maxwellian or Einsteinian schools; there is simply physics. In linguistics, there is no Chomskian school; there is simply linguistics. Though psychotherapy is not yet at the level of a science, we can foster an attitude of scientific inquiry, based in respect for the clinician's craft. We can encourage more naturalistic observation and open sharing of therapeutic work, using what ever methodology seems appropriate to the question being explored. Most of all, we can cultivate an attitude of humility, curiosity and wonder at human resiliency, acknowledging that we are still far from understanding the active principles in recovery from psychological trauma. 


\section{$\underline{\text { References }}$}

Chomsky, N. (1988). Language and Problems of Knowledge. Cambridge, MA: MIT Press. Quote on p. 1.

Foa, E.B., Keane, T.M., \& Friedman, M.J., Eds. (2000): Effective Treatments for PTSD: Practice Guidelines form the International Society for Traumatic Stress Studies. New York: Guilford.

Goode. E. (2002). Antidepressants lift clouds, but lose 'miracle drug' label. New York Times, June 30, p.1.

Herman, J.L. (1997). Trauma and Recovery ( $2^{\text {nd }}$ Ed.). New York: Basic Books. Herman, J.L. \& Schatzow, E (1984). Time-limited group therapy for women with a history of incest. International Journal of Group Psychotherapy 34:605-616.

Lewis, H.B. (1971). Shame and Guilt in Neurosis. New York: International Universities Press.

Miller, J.B. \& Stiver I.P. (1997). The Healing Connection: How Women Form Relationships in Therapy and in Life. Boston, MA: Beacon Press.

Ogden, P., Minton, K., \& Pain, C. (2007). Trauma and the Body: A Sensorimotor Approach to Psychotherapy. New York: Norton.

Rush, A.J., Trivedi, M.H., Wisniewski, S.R., Nierenberg, A., Stewart, J.W., \& Warden, D., et. al. (2006). Acute and longer-term outcomes in depressed outpatients who required one or several treatment steps: A STAR*D report. American Journal of Psychiatry, 163:1905-1917. 
Spinazzola, J., Blaustein, M., \& van der Kolk, B.A. (2005). PTSD treatment outcome research: The study of unrepresentative samples? Journal of Traumatic Stress 18: 425436.

Truax, C.B. \& Carkhuff, R.R. (1967). Toward Effective Counseling and Psychotherapy. Chicago IL: Aldine.

Westen, D. \& Morrison K. (2001). A multidimensional meta-analysis of treatments for depression, panic, and generalized anxiety disorder: An empirical examination of the status of empirically supported therapies. Journal of Consulting and Clinical Psychology 69: 875-899. 